\title{
Um estudo sobre o gênero digital HQtrônica em língua inglesa
}

\author{
Luana Fossatti Testa ${ }^{1}$ \\ Didiê Ana Ceni Denardi²
}

Siderlene Muniz Oliveira ${ }^{3}$

\begin{abstract}
Resumo
Devido às inúmeras transformações que o contexto educacional vem sofrendo nos últimos anos, o professor necessita desenvolver um trabalho que desperte o interesse dos alunos. Isso pode ser possível por meio dos gêneros digitais. Objetivamos neste artigo analisar o gênero digital HQtrônica, para posterior construção de um modelo didático e de sequências didáticas. Embasamo-nos na abordagem teórica do Interacionismo Sociodiscursivo, dos gêneros textuais e digitais, HQtrônicas, multimodalidade e ressemeotização. Na análise verificou-se a situação de produção, os mecanismos textuais e enunciativos, e os processos multimodais e ressemióticos do gênero. Foi possível concluir que o gênero digital HQtrônica é um importante objeto de estudo a ser utilizado pelo professor no ensino de línguas.

Palavras-chave: Modelo Didático; HQtrônica; Gêneros Digitais.
\end{abstract}

\section{A study on the digital genre "hypermedia comics" in English language}

\section{Abstract}

Due to many transformations that the educational context has been facing in the last few years, the teacher needs to develop a work that rouses the students' interest. This may be possible with the digital genres. This article aims to analyze the digital genre named hypermedia comics, to further building a didactic model and some didactic sequences. This article is based on the theoretical approach of Sociodiscursive Interactionism, textual and digital genres, hypermedia comics, multimodality and resemeotization. In the analysis, it was verified the communicative situation, textualization and enunciative mechanisms, and the multimodal and resemiotic processes of the genre. It was concluded that the digital genre hypermedia comics is an important object of study to be used by the teacher in the teaching of languages.

Keywords: Didactic model; Hypermedia comics; Digital genres.

\section{Introdução}

Considerando as diversas transformações sociais e tecnológicas ocorridas nos últimos anos, os indivíduos acabam se adaptando a essa multiplicidade de formas de viver, comunicar, aprender e interagir em sociedade. No contexto educacional, a maneira de chamar a atenção

\footnotetext{
${ }^{1}$ Universidade Tecnológica Federal do Paraná, Pato Branco/PR, luanatesta@hotmail.com

${ }^{2}$ Universidade Tecnológica Federal do Paraná, Pato Branco/PR, didie@utfpr.edu.br

${ }^{3}$ Universidade Tecnológica Federal do Paraná, Dois Vizinhos/PR, smoliveira@utfpr.edu.br
} 
dos educandos para o ensino tornou-se um desafio, cabe ao professor a difícil tarefa de criar pontes entre a realidade do aluno e a realidade mundial, e isso pode ser possível através do trabalho com gêneros digitais que despertem o interesse dos alunos.

Para Costa (2005), formar indivíduos questionadores, criativos e autônomos, pressupõe considerar o aluno como sujeito do processo ensino-aprendizagem e o professor como mediador entre o aprendiz e o conhecimento, provocador de dúvidas, curiosidades e questionamentos. Neste contexto, observa-se que a instituição escolar e o professor não podem ignorar as novas tecnologias/ferramentas de comunicação, portanto, o principal desafio do professor é utilizar diferentes recursos midiáticos, aproximando o educando da realidade em que está inserido, possibilitando a construção do conhecimento.

Este artigo tem como objetivo analisar o gênero digital história em quadrinhos (HQtrônica), explorando as particularidades desse gênero e destacando os avanços tecnológicos que aconteceram na linguagem dos quadrinhos, principalmente na sua gramática específica, sua infraestrutura e seu contexto e meio de produção. A análise contribuirá para posterior elaboração de um modelo didático e sequências didáticas (SDs) que podem ser utilizadas no processo de ensino-aprendizagem.

Dessa forma, o presente trabalho é justificado na necessidade de compreender as características do gênero digital HQtrônica, utilizando-o no contexto escolar, precisamente nas aulas de Língua Inglesa, transformando-o em objeto de ensino. Além disso, esse gênero por apresentar a linguagem e a imagem em movimento no contexto digital, constitui-se de uma ferramenta motivadora para o ensino e a aprendizagem, sendo possível desenvolver as capacidades de linguagem dos alunos.

A fim de atingir o objetivo, este artigo está dividido da seguinte forma: inicialmente, apresentamos alguns conceitos dos pressupostos teóricos que orientam a pesquisa. Posteriormente, tratarei da metodologia da pesquisa e, sequencialmente, mostrarei o levantamento de dados do episódio 1, da série da HQtrônica Batman: Legends of The Dark Knight. Finalmente, a partir das análises realizadas, apresentaremos, em síntese, as principais características de uma HQtrônica e as considerações finais. 


\section{Ensino-aprendizagem na perspectiva de Gêneros Textuais}

Esta pesquisa baseia-se nas proposições de modelização didáticas de gêneros de texto de Bronckart (2012), Schneuwly e Dolz (1999/2004). A pesquisa utiliza-se da teoria do Interacionismo Sociodiscursivo (doravante ISD), que foi elaborada pelos pesquisadores acima mencionados, em Genebra. O ISD baseia-se na psicologia histórico-social de Vygotsky e nas proposições teórico-sociais de gênero de Bakhtin.

Segundo Bronckart (2012), a teoria do ISD fundamenta-se no processo de desenvolvimento e funcionamento das condutas humanas, no qual o desenvolvimento humano acontece por meio das diversas construções sociais do indivíduo e no seu processo de formação, dessa forma, a linguagem possui o papel primordial nesse processo, pois é através dela que organizamos, regulamos, agimos e interagimos. Por essa razão, Schneuwly e Dolz (2004) defendem que gêneros textuais orais ou escritos precisam ser aprendidos sistematicamente para o desenvolvimento das capacidades de expressão oral e escrita dos alunos, sendo isso tarefa da escola.

Para Machado (2009), o ISD defende a tese de que o desenvolvimento dos indivíduos ocorre em atividades sociais, em um meio constitutivo e organizado por diferentes préconstruídos e através de processos de mediação, sobretudo, o linguareiro. Em outras palavras, o ISD é compreendido dentro da sua dinamicidade sócio-histórica, considerando a língua como ferramenta de interação social; tal abordagem contribui para aprofundar o estudo sobre a relação entre pensamento, linguagem e agir humano. Assim, as atividades e produções de linguagem que ocorrem em construções sociais conduzem à aprendizagem, à conscientização e ao desenvolvimento humano.

De acordo com as Diretrizes Curriculares de Língua Portuguesa para a Educação Básica (PARANÁ, 2006), é necessário que o professor trabalhe com gêneros textuais para que, assim, o aluno desenvolva sua capacidade de leitura crítica, sendo capaz de compreender através de textos que os significados são sociais e historicamente construídos e, portanto, passíveis de transformação na prática social.

Segundo Bronckart (2012), todo o indivíduo, desde o momento do nascimento, é exposto e confrontado com inúmeros textos já existentes, que são organizados em gêneros, e é essa 
exposição contínua aos gêneros que vai nos tornando leitores e produtores de um conhecimento intuitivo, de propriedades específicas de diversos gêneros. Bakhtin (2003) define os gêneros como formas relativamente estáveis de enunciados, pois suas propriedades gerais são apropriadas pelos indivíduos, mas acabam sofrendo modificações de acordo com momento sócio-histórico e de acordo com o desenvolvimento do indivíduo. Assim como os gêneros, consideramos que um "modelo didático" também é relativamente estável, sendo preciso que seja realizado um levantamento das características linguístico-discursivas, a fim de que o professor conheça e domine o gênero antes de apresentar aos alunos.

No ensino de gêneros, é preciso que os sujeitos se apropriem do texto em estudo e os considerem úteis para seu agir com a linguagem, pois se os aprendizes não sentirem a necessidade de determinado gênero para o agir verbal, haverá também uma grande dificuldade para a apropriação (MACHADO; CRISTOVÃO, 2006).

Em outras palavras, Dolz, Noverraz e Schneuwly (2004) e Cristovão e Stutz (2011) afirmam que o ensino de cada gênero textual possibilita o desenvolvimento de operações que estão relacionadas às capacidades de linguagem, que são designadas e definidas pelos autores como:

- A capacidade de ação: nessa capacidade, o sentido é buscado através das representações dos elementos do contexto de produção dos conteúdos, ou seja, consiste em saber reconhecer o contexto da produção textual (quem produziu, quem é o receptor, quando e onde foi produzido, o que se objetiva com o texto).

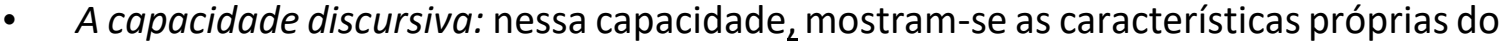
gênero a ser estudado através da planificação global do texto, a estrutura do texto (layout, sequência textual, tipos de linguagem e discurso).

- A capacidade linguístico-discursiva: nessa capacidade centram-se as unidades linguístico-discursivas das sentenças que auxiliam na compreensão do texto; os mecanismos de textualização e enunciativos, os elementos organizacionais, conectores que estabelecem a coesão e a coerência.

- A capacidade de significação: nessa capacidade, mostram-se questões mais amplas do gênero, observando com criticidade o gênero, construindo sentidos sobre práticas sociais.

Dessa forma, no que se refere à transposição de gêneros textuais em objetos de ensino, Schneuwly, Noverraz e Dolz (2004) afirmam ser necessário a construção de um modelo didático 
do gênero a ser estudado/ensinado para nortear o (a) professor (a) no levantamento de elementos ensináveis desse mesmo gênero, possibilitando a elaboração de uma determinada sequência didática.

Portanto, o modelo didático de gênero consiste na descrição de um determinado gênero textual. Para a descrição de um gênero, recorre-se ao reconhecimento do contexto social para o qual se pretende elaborar a sequência didática, aos estudos já realizados sobre o gênero e à análise de um corpus de textos utilizado nas práticas sociais de referência. Segundo Schneuwly, Noverraz e Dolz (2004), uma sequência didática tem como finalidade ajudar os alunos a se apropriarem de um gênero textual, possibilitando escrever e falar de maneira adequada a cada situação de comunicação.

Assim, a construção de uma sequência didática torna-se bem mais simples com a definição dos objetivos de ensino de gênero adaptados ao nível de conhecimento dos alunos, em que as atividades efetivamente desenvolvidas possam exigir do professor um retorno ao modelo didático para modificá-lo (MACHADO; CRISTOVÃO, 2006).

\section{Gêneros digitais}

De acordo com Marcuschi (2005), na atual ascensão da denominada cultura eletrônica, com o telefone, o gravador, o rádio, a TV e, especialmente, o computador e a internet, houve uma explosão de novos gêneros e novas formas de comunicação, tanto na oralidade como na escrita, surgindo, então, os gêneros digitais.

Com as tecnologias surgiram várias inovações e transformações no meio digital, mas que na realidade não são novas, apenas sofreram mudanças. Assim como os gêneros são relativamente estáveis, estando sujeitos à transmutação e assimilação de um gênero por outro, gerando novos gêneros, afirma Bakhtin (1997). Portanto, os gêneros digitais nada mais são do que "evoluções, adaptações ou modificações dos textos orais e escritos para o contexto virtual e não necessariamente o surgimento de novos gêneros" (SARDINHA, 2011, p.3).

Marcuschi (2005) conceitua os gêneros digitais como aqueles que trabalham com o discurso eletrônico, ou seja, são aqueles que apresentam como suporte o computador. Para Marcuschi (2005), um dos aspectos mais marcantes dos gêneros em ambientes digitais é que são 
interativos, estabelecendo assim aspectos nas relações entre fala-escrita, pois possibilitam a inserção de elementos visuais no texto (imagens, fotos) e sons (músicas, vozes), efetivando, assim, a "integração de recursos semiológicos" (MARCUSCHI, 2005, p. 18).

\section{Histórias em quadrinhos e HQtrônica}

McCloud (1995) define as HQs como ilustrações justapostas em uma sequência, podendo ser acompanhadas ou não de um texto escrito, ou seja, são uma sequência de dois ou mais quadros que criam uma narrativa visual.

Conforme estudos de Stutz; Biazi (2007), as HQs apresentam determinadas características específicas nos seguintes elementos:

- $\quad$ Elementos Narrativos: personagens, tempo, espaço, narração.

- $\quad$ Elementos Visuais: Estilos de traços, quadros, vinhetas, enquadramento, figuras cinéticas e metáforas visuais.

- $\quad$ Elementos Verbo-Visuais: balão, legenda, onomatopeias.

A partir das HQs tradicionais surgiram as histórias em quadrinhos digitais, sendo que Franco (2008) as nomeou de HQtrônicas quando incluem as histórias em quadrinhos que unem um (ou mais) dos códigos da linguagem tradicional das HQs no suporte papel com uma (ou mais) das novas possibilidades abertas pela hipermídia. Dessa forma, a definição exclui as HQs que são simplesmente digitalizadas e transportadas para a tela do computador, sem usar nenhum dos recursos da hipermídia destacados.

Franco (2008) ressalta que a utilização de recursos digitais colaborou para que novos elementos fossem agregados às HQtrônicas, tais como:

a) Animação: define-se como "uma ilusão de ótica gerada pela apresentação de uma série de imagens (não filmadas), o que ocasiona a impressão de movimento devido ao fenômeno da retenção retiniana, no qual os olhos retêm qualquer imagem no intervalo de tempo que vai de 1/10 a 1/17 segundos" (MORAES, 2011, p. 104).

b) Diagramação dinâmica: utiliza os recursos da animação para produzir mobilidade aos quadros para que se expandam ou que se movam na página;

c) Interatividade: permite ao leitor intervir nos rumos da narrativa que apresenta 
múltiplos caminhos;

d) Trilha sonora: emprega um tema musical instrumental;

e) Efeitos sonoros: implanta recursos sonoros para substituir as onomatopeias;

f) Tela infinita: permite novas experimentações de diagramação e narração para os webquadrinhistas e para o leitor, com a utilização de barras de rolagens verticais e horizontais e de zooms para imergir no interior dos quadrinhos;

g) Tridimensionalidade: possibilita a produção de objetos e personagens em 3D;

h) Narrativa multilinear: promove narrativas paralelas para o leitor, com duas possibilidades de continuação da narrativa e, também, uma disponibilidade de links, relacionados ao roteiro da história.

Sendo assim, esse gênero pode ser uma importante ferramenta pedagógica em sala de aula, pois nossos alunos fazem parte de uma época em que cada vez mais a imagem e as palavras se associam, e só trabalhando dessa forma é que eles estarão produzindo sentidos nos diversos contextos comunicativos e sociais.

\section{Multimodalidade e ressemiotização}

Kress e Van Leeuwen (2006, p. 113) explicam que a multimodalidade é "uma interação semiótica na qual cada modo, o verbal e o visual, possuem funções iguais a desempenhar". Dessa forma, quando nossas palavras não são suficientes para expressar algo, utilizamos gestos, expressões faciais, desenhos e uma série de outros recursos.

Para os autores, à medida que o uso da tecnologia cresce, os textos tornam-se cada vez mais multimodais e híbridos, uma vez que as ferramentas tecnológicas possibilitam a inserção dos mais diversos recursos nos textos.

Dionísio (2005, p. 159) afirma que "os fenômenos multimodais estão presentes nas ações sociais e nos gêneros textuais orais e escritos"; portanto, o grau de informatividade visual dos gêneros textuais da escrita se processa num contínuo e há novas formas de interação entre o leitor e o texto, resultantes da estreita relação entre o discurso e as inovações tecnológicas.

ledema (2003) utiliza o termo ressemiotização, o qual trata de entender como ocorre a ressignificação de recursos semióticos quando um texto é deslocado de seu contexto primário 
de circulação para instâncias secundárias de comunicação. Segundo o autor, a ressemiotização tem a função de fornecer meios analíticos para investigar como sistemas semióticos são transpostos de um contexto para outro e em que medida processos sociais específicos se desdobram nessa transposição.

Dessa forma, o gênero digital HQtrônicas pode ser caracterizado como um objeto ressemiotizado, pois muitas ferramentas tecnológicas comandam o processo de criação dos quadrinhos, possibilitando uma ruptura nos padrões do gênero impresso $H Q$. O uso das onomatopeias, por exemplo, há a possibilidade de introduzir sons e efeitos sonoros que dinamizam sua forma sonora e visual. Os movimentos das cenas, as opções de efeitos visuais e o próprio arranjo da página da internet conferem aos quadrinhos híbridos características bem peculiares, pois podem "usufruir o máximo possível dos recursos multimidiáticos, não-lineares e interativos que somente um ambiente virtual em uma rede sociotécnica pode congregar" (MALLET, 2009, p. 84).

\section{Metodologia}

Selecionamos o episódio 1 da série da HQtrônica Batman: Legends of The Dark Knight (Batman: Lendas do Cavaleiro das Trevas), o qual tem como título: "The Butler Did It" (A culpa é do mordomo) e encontra-se disponível no site youtube. ${ }^{4}$ A série foi lançada em 2012 e conta com seis episódios curtos e sem continuação, retratando histórias de crimes e ficção enfrentadas pelo personagem Batman. Porém, nossa análise destina-se somente ao episódio 1, que tem duração de sete minutos e oito segundos.

O estudo que desenvolvemos foi elaborado para que o professor ou pesquisador possa conhecer as características principais do gênero em questão, para posterior elaboração de um modelo didático e de uma sequência didática, a ser aplicada nas aulas de Língua Inglesa, para alunos do Ensino Médio.

Construímos nossa análise com base nos seguintes elementos do gênero HQtrônica: a situação de produção do gênero, em seguida os mecanismos textuais: nível de textualização e

\footnotetext{
${ }^{4}<$ https://www.youtube.com/watch?v=G6KS zl9uBQ> Acesso em: 27 de set. de 2019.
} 
enunciativo e por fim, analisamos os processos multimodais e ressemióticos na transposição da história em quadrinho tradicional para a HQtrônica.

\section{Análise da HQtrônica: contexto de produção}

De acordo com o site "HQ rock" ${ }^{5}$, o personagem Batman foi lançado na revista Detective Comics, dos Estados Unidos, no dia 27 de maio de 1939, em um conto de oito páginas denominado "O caso do sindicato dos químicos". Batman, também conhecido como Homem-Morcego, aqui no Brasil, é um herói na cidade de Gotham. Durante o dia, ele é o filantropo e bilionário Bruce Wayne e nas madrugadas ele se torna um herói, combatendo criminosos nas ruas da sua cidade.

Batman rapidamente tornou-se conhecido e transformou-se em um dos principais personagens da literatura ficcional. Além disso, não fez sucesso apenas nos quadrinhos, mas também em desenhos animados, vídeos games e livros. Algumas obras clássicas do herói marcaram o mundo literário, como: Ano Um, Cavaleiro das Trevas, Asilo Arkham, a Piada Mortal.

No ano de 1989 foi lançada a coleção de histórias em quadrinhos intitulada Batman: Legends of The Dark Knight (Batman: Lendas do Cavaleiro das Trevas). Grande parte dessas histórias retratavam o início da carreira de Batman. No ano de 2012, a DC Comics lançou para o meio digital, a minissérie semanal Batman: Legends of The Dark Knight, que teve seis edições, a primeira delas, objeto de nossa análise, foi lançada no dia 07 de junho de 2012 e chamada de "The Butler Did It" (A culpa é do mordomo).

As seis edições dessa série também foram disponibilizadas em livros impressos no mesmo ano de lançamento das histórias no meio digital. A HQtrônica que selecionamos para o levantamento de suas características encontra-se disponível na página do youtube, tratando-se da primeira edição da série Batman - Lendas do Cavaleiro das Trevas, tem como título "The butler did it", traduzida como "A culpa é do mordomo".

A HQtrônica foi produzida em 2014 e publicada no site no mês de agosto de 2014, por

\footnotetext{
${ }^{5}<$ https://hqrock.com.br/2011/11/08/batman-a-trajetoria-do-homem-morcego-nos-quadrinhos/> Acesso em: 27 de set. de 2019.
}

Periódico Horizontes - USF - Itatiba, SP - Brasil - e020009 
IhKo Media que é um canal do youtube em que se encontram motion comics produzidas por fãs. Os responsáveis pelos sons e músicas são Jennifer Eberhardt; pelas vozes, Philippe Bernaerts como Batman/Bruce Wayne, e Alfred Erick Abraham, como Joker laughing e Jim Chaudrue como Thug; publicação da história DC escrita por Damon Lindelof e desenhada por Jeff Lemire, direção de Marc Ihlow IhKo Media, 2014.

\section{A história "O cavaleiro das trevas" - série Batman}

A narrativa se passa em Gotham City, cidade fictícia das histórias em quadrinho da $D C$ Comics, apresenta semelhanças com grandes cidades do mundo, onde existe altos índices de criminalidade e corrupção. Batman está em seu sexto mês de atuação, e a narrativa o mostra como um jovem comprometido com sua guerra particular e excessivamente prepotente. Bruce enxerga os criminosos como meros ratos de rua afugentados e, durante uma conversa com Alfred, seu mordomo, deixa escapar um profundo desprezo pelas habilidades de alguns de seus colegas de liga (principalmente Hal Jordan). Tamanha soberba o faz crer que era invulnerável, contudo, o objetivo da história é provar exatamente o contrário.

Em uma de suas saídas noturnas, Batman vê um homem segurando uma família à mão armada em um beco e pula sobre o atirador. Pressionando o homem contra a parede, ele avisa: "Sem família. Sem filhos". O bandido sorri, revelando que era uma armadilha. Ele se pergunta qual psicopata deve ter organizado isso.

Batman lembra-se de como, mais cedo, estava se gabando com Alfred Pennyworth sobre como sua falta de poder o tornava menos vulnerável do que outros heróis. Ele acreditava que ele era invulnerável, porém, Alfred sugeriu que todo homem tem uma vulnerabilidade. Bruce, teimosamente, se recusou a acreditar nisso, e apostou com seu mordomo um dólar que ele era invulnerável.

Por fim, espancado e quebrado, Batman abre os olhos para ver os homens que o espancaram enquanto Alfred se aproxima. Seu amigo e mordomo cumprimenta-o, enfia a mão no cinto de utilidades e retira uma nota de um dólar. A história termina com Alfred proferindo a seguinte frase: "Everyone has a vulnerability, yes?"; ficando certo suspense no ar.

Quanto ao plano geral da HQtrônica, analisada identificou-se que o episódio possui os 
créditos de abertura e de encerramento, a mesma música é utilizada, enquanto os créditos são mostrados, tanto no início quanto no final, os cenários são os seguintes: história se inicia à noite, com o tempo chuvoso, mostra alguns prédios da cidade de Gotham, as ruas e edifícios os quais Batman escala e voa, também é possível ver o lado de fora da mansão Wayne em que Batman reside, e através de um flashback podemos adentrar a mansão, onde Batman dialoga com seu mordomo em uma sala de jantar, e finalmente, a história termina na rua, o tempo continua chuvoso.

Quanto ao tempo cronológico, a história se passa no período da noite, não é possível identificar a data precisa, somente que fazem seis meses em que Bruce está atuando em sua profissão de Batman, e a história se passa em poucas horas, porém, não é possível identificar quanto tempo ele ficou desacordado, mas quando acordou ainda estava escuro e chovendo.

Os personagens da história são poucos, Bruce (Batman) que é o personagem principal, conhecido por combater o crime, seu mordomo Alfred Pennyworth e os quatro vilões que armaram a emboscada para Batman, além disso, aparecem outros personagens: Killer Croc, a Mulher-gato, Coringa, Duas faces, Mister Freeze, Hera Venenosa, porém, esses personagens não fazem parte da história, apenas aparecem no sonho ou delírio de Batman, enquanto estava desacordado.

A HQtrônica tem na maior parte da narrativa um narrador personagem (Batman), que narra em primeira pessoa. Além disso, temos também o discurso interativo dialogal, entre Batman e os bandidos, entre Batman e o mordomo e de Batman com ele mesmo, quando se questiona.

\section{Nível de textualização e enunciativo - coesão verbal e nominal, vozes}

No que se refere aos níveis de textualização e enunciativo, percebe-se que os tempos verbais presentes na narrativa são em sua maioria verbos no passado (regulares e irregulares), porém, existem muitos verbos no presente simples, alguns no presente contínuo e futuro, e poucos no presente e passado perfeito, além disso, aparecem durante as falas, além da forma afirmativa, as formas negativas e interrogativas dos verbos acima, também podemos identificar os verbos modais.

A linguagem utilizada nas falas dos personagens é predominante formal, os personagens não utilizam gírias, nem palavrões, podemos observar nos excertos abaixo: 
Quadro 1 - Linguagem predominante

\begin{tabular}{|l}
\hline "When a new predator is introduced into their habitat, the rats have a choice..." \\
- "But that was before I understood there is no such thing as peace." \\
- "That will be quite enough, thank you."
\end{tabular}

Fonte: Trecho de transcrição da HQtrônica. Disponível em: https://www.youtube.com/watch?v=G6KS zl9uBQ. Acesso em 27 de set. 2019

A narrativa tem uma linearidade, apresentando apenas um flashback, o qual é possível identificar com facilidade; o vocabulário é bem estruturado, de fácil compreensão, com frases completas e poucas abreviações de palavras. Porém, encontramos algumas contrações nas palavras, as quais são normais, visto se tratar da linguagem oral. Percebe-se que há coesão nominal, com presença de anáforas pronominais, ou seja, os pronomes pessoais, possessivos, demonstrativos e muitas preposições, como nos trechos abaixo:

Quadro 2 - Contração de palavras e anáforas pronominais

\begin{tabular}{|ll|}
\hline & "That's what superates me from them." \\
$\bullet$ & "That's why I' II always win." \\
\hline
\end{tabular}

Fonte: Trecho de transcrição da HQtrônica. Disponível em: https://www.youtube.com/watch?v=G6KS zl9uBQ. Acesso em 27 de set. 2019

No que se refere as vozes enunciativas podemos encontrar somente as vozes dos personagens. Também encontramos modalizadores do enunciado em frases exclamativas, interrogativas e o uso de reticências. Vejamos um trecho do diálogo entre Batman e Alfred, o mordomo, no qual é possível identificar as vozes enunciativas e alguns modalizadores:

Quadro 3 - Vozes enunciativas e modalizadores

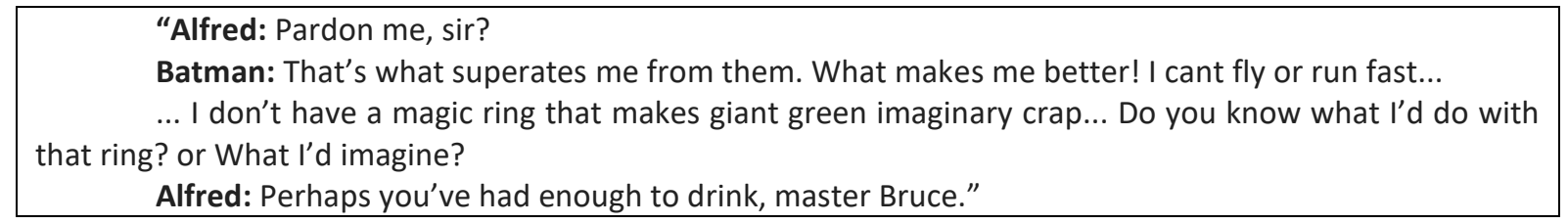

Fonte: Trecho de transcrição da HQtrônica. Disponível em: https://www.youtube.com/watch?v=G6KS z|9uBQ. Acesso em 27 de set. 2019

Percebe-se que os modalizadores indicam entonações, incertezas, alegrias, indagações, marcadores esses típicos de narrativas dialogadas e que permitem compreendermos melhor o sentido dos enunciados. 


\section{Multimodalidade e ressemiotização}

Apresentamos, a seguir, os processos de multimodalidade e ressemiotização, em relação aos seguintes elementos presentes na HQtrônica: balão, recordatórios, cores, animação das personagens e objetos, animação de enquadramento de cenas, efeitos sonoros.

A compreensão das representações na narrativa pode ser efetuada pela associação entre o processo verbal (fala das personagens) e a identificação das imagens em forma de balões e recordatórios (KRESS; VAN LEEUWEN, 2006). Na HQtrônica analisada há os dois elementos, ou seja, a fala oral dos personagens e escrita nos balões. O balão, como um dos elementos caracterizadores da linguagem tradicional dos quadrinhos em suporte de papel, é ressemiotizado como forte elemento da linguagem da HQtrônica (IEDEMA, 2003). O tipo de balão recorrente na HQtrônica analisada é o balão-fala: de traçado contínuo, na cor branca, utilizado para que as personagens da narrativa dialoguem por meio dele. Além disso, aparecem os balões retangulares que são os trechos da história narradas pelo narrador autodiegético, os balões são tracejados continuamente, de diferentes tamanhos, e aparecem em diferentes posições da imagem, todos da cor branca e cinza. As Figuras 1 e 2 ilustram os tipos de balões:

Figura 1 - Tipos de balões

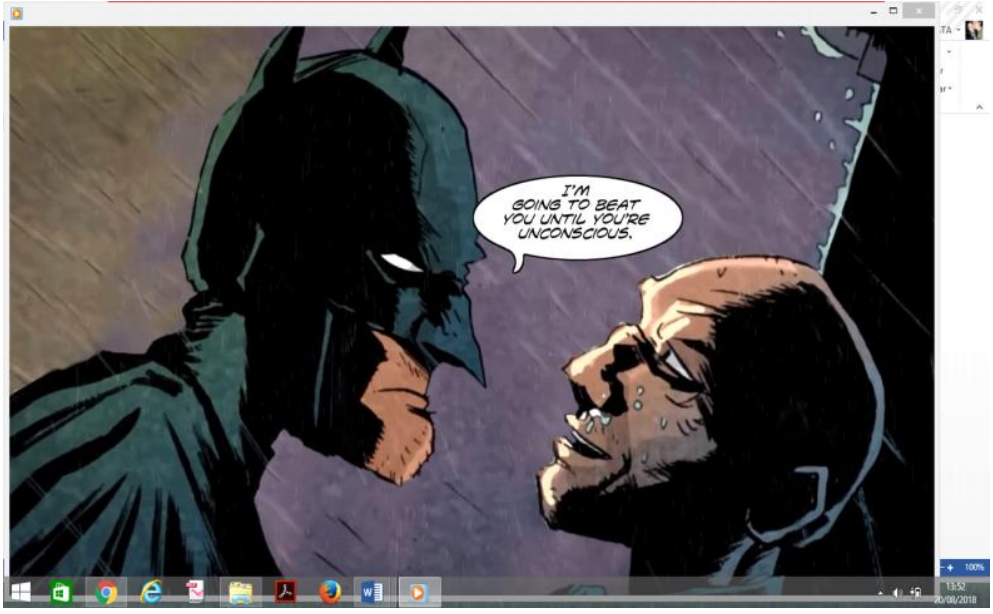

Fonte: Cena da HQtrônica. Disponível em: https://www.youtube.com/watch?v=G6KS zl9uBQ. Acesso em 27 de setembro de 2019 
Figura 2 - Tipos de balões

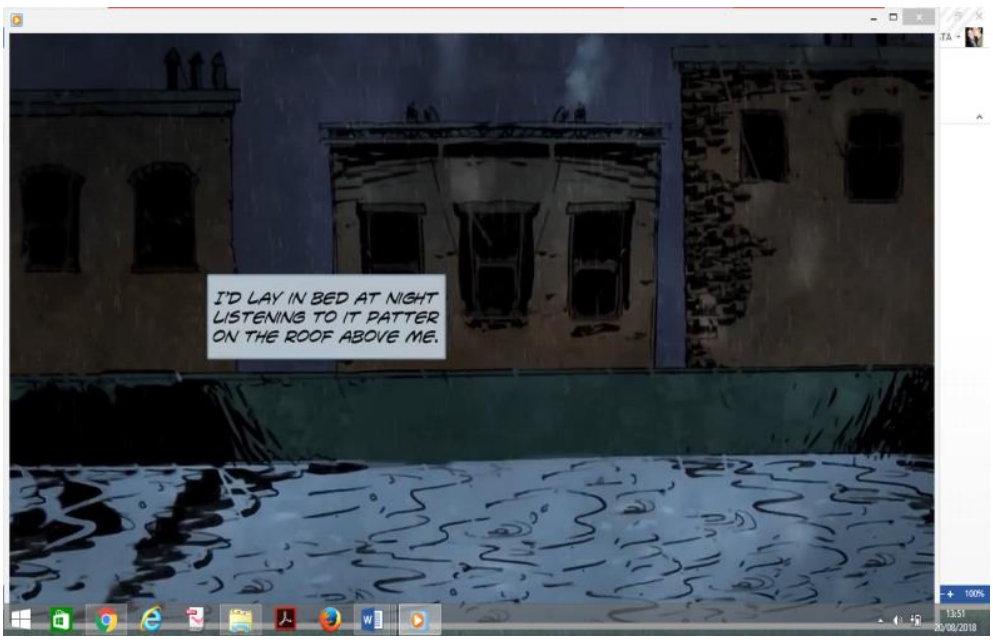

Fonte: Cena da HQtrônica. Disponível em: https://www.youtube.com/watch?v=G6KS_zl9uBQ. Acesso em 27 de setembro de 2019

As cores predominantes na história são as cores escuras, tons de preto, cinza, azul escuro, representando a noite, o suspense, o tempo nebuloso e chuvoso, os perigos. Uma das cenas em que o Batman é ferido, a cor primária que prevalece é a vermelha, representando o sangue, a dor, as feridas, além de ser uma cor que causa uma sensação mais forte em quem está vendo. De acordo com Kress; Van Leeuwen (2006), a composição e contraste das cores nos auxiliam tanto a entender os significados representados na imagem quanto a compreender a valoração simbólica dessas cores para a trama (KRESS; VAN LEEUWEN, 2006). As cenas da Figura 3 são exemplos das cores predominantes na HQtrônica: 


\section{HSE}

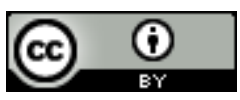

DOI: https://doi.org/10.24933/horizontes.v38i1.871

Figura 3 - Cores Predominantes
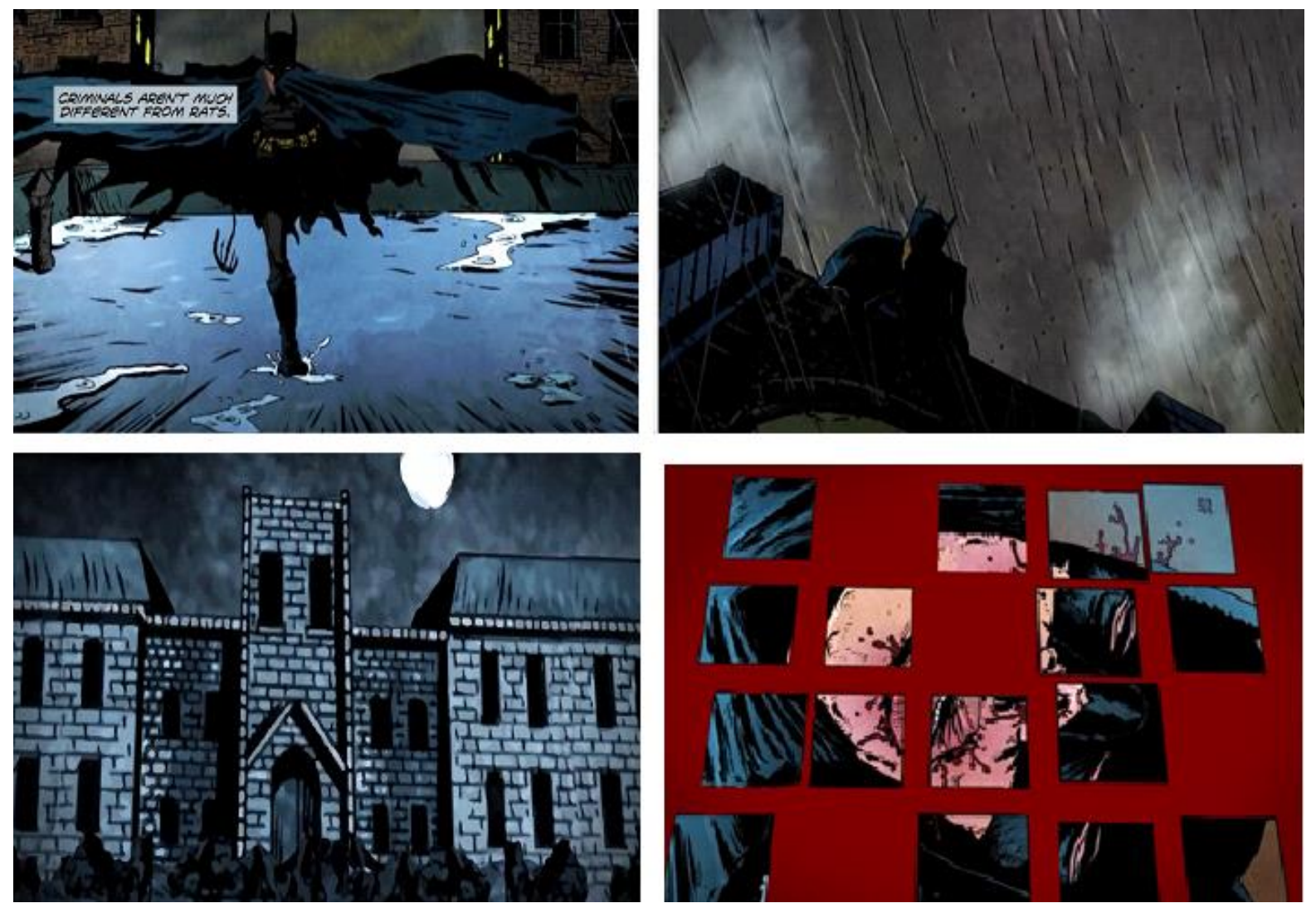

Fonte: Cenas da HQtrônica. Disponível em: https://www.youtube.com/watch?v=G6KS zl9uBQ. Acesso em 27 de setembro de 2019

A HQtrônica utilizou o programa Flash da Macromedia e permitiu a inclusão dos seguintes recursos digitais: animação das personagens, animação de enquadramento de cenas, efeitos sonoros e trilha sonora. Ao ser transferida para o suporte online, a HQtrônica recebeu semioses que não estavam presentes em seu suporte impresso, ou seja, ela foi ressemiotizada (IEDEMA, 2003) para produzir novos significados. Na HQtrônica analisada percebe-se as animações dos personagens, os quais andam, conversam, correm, lutam, saltam, além de movimentarem o corpo, gesticularem e ainda utilizam expressões faciais, capazes de representar os sentimentos. As personagens também foram enriquecidas por novas semioses (IEDEMA, 2003), como o movimento do corpo e a presença da voz, que colaboram para a veracidade das cenas e para compor o fluxo dos acontecimentos. Na Figura 4, podemos ver algumas exemplificações desse recurso: 
Figura 4 - Animação dos personagens.
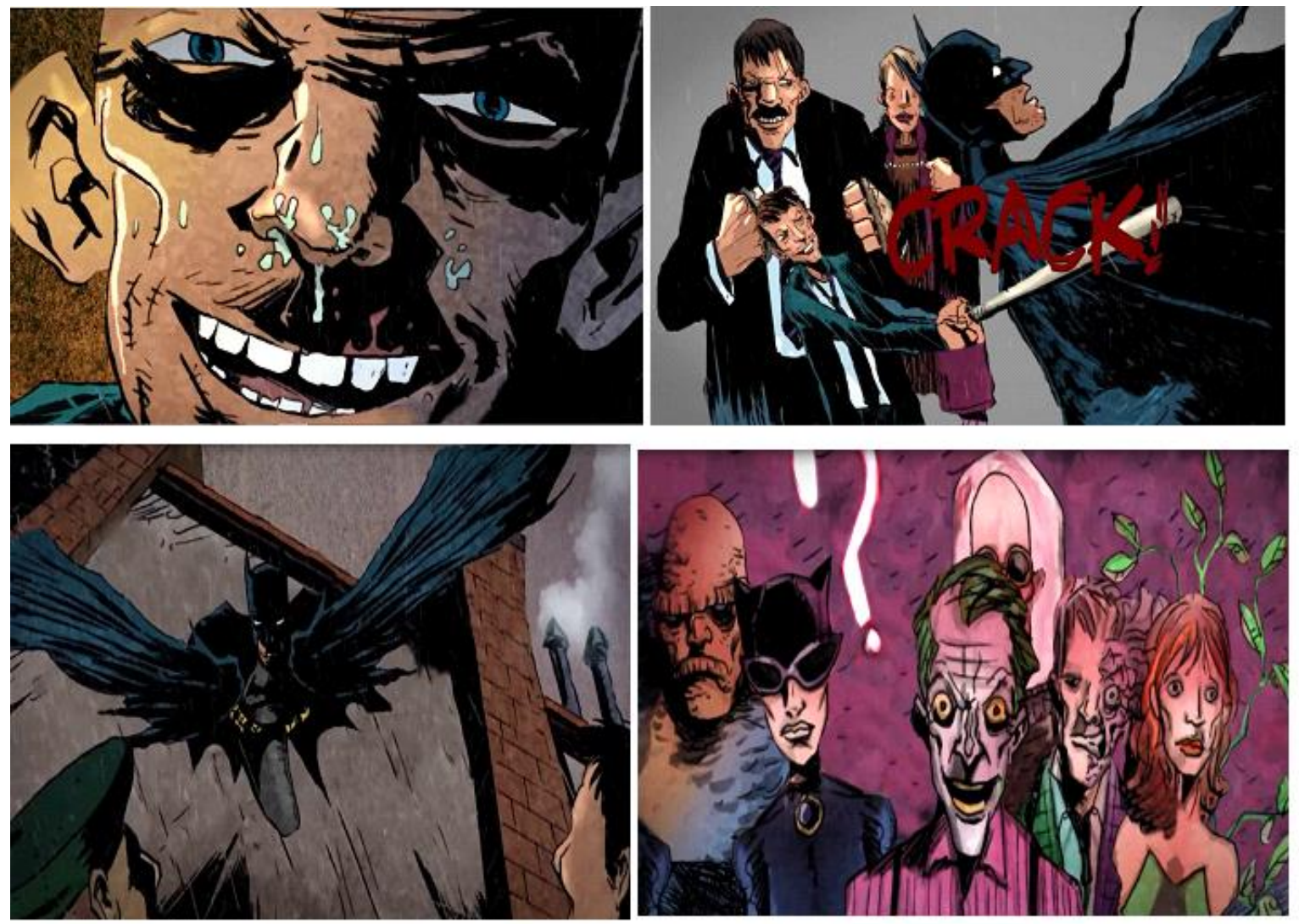

Fonte: Cenas da HQtrônica. Disponível em: https://www.youtube.com/watch?v=G6KS zl9uBQ. Acesso em 27 de setembro de 2019

Identificamos cenários ressemiotizados que, de acordo com Idema (2003), representam uma riqueza de detalhes e ações, como o movimento e o som da chuva, de trovões, sons, movimento e luzes dos raios, fumaça saindo de chaminés, folhas e plantas se movendo, objetos sendo movidos (copos e garrafa), sangue escorrendo pelo rosto, sons de sinos tocando.

As animações de enquadramentos da HQtrônica indicam a maneira como um quadro é apresentado ao leitor. Em Batman: Legends of The Dark Knight, embora haja a utilização do enquadramento de cenas em nível de plano detalhe, focalizando detalhes das personagens ou de objetos, o enquadramento predominante é o de plano geral, ou seja, mais abrangente, incluindo as personagens e cenários em sua totalidade. $\mathrm{O}$ enquadramento ressemiotizado a partir de elementos cinematográficos (IEDEMA, 2003) busca evidenciar a relação existente entre as imagens que compõem esse conjunto e mostrar que elas produzem uma significação maior que elas não teriam por si mesmas isoladamente. Além disso, a diagramação dinâmica foi 
utilizada para transformar as páginas dos quadrinhos em cenas, adequando cada cena ao formato da tela do computador, assim, a diagramação buscou detalhar as características físicas de cada personagem, o cenário e exaltar as cores, intensificando, assim, a emoção da trama.

Tanto a ressemiotização (IEDEMA, 2003) da diagramação dinâmica quanto dos efeitos sonoros revelam autenticidade, criatividade e detalhamento na produção das cenas, o que torna a trama mais enriquecida.

Enfim, os efeitos sonoros existentes na história são vários, como barulhos da chuva, de trovões, de passos das pessoas na rua e em casas, água gotejando, sinos tocando, campainha tocando, batida de um cassetete, gemido, gritos de dor. Além disso, no início e no final da trama é tocada uma música instrumental, e em alguns momentos foram utilizadas músicas instrumentais que trazem ao telespectador um determinado suspense, sendo possível visualizar todos esses recursos acessando a HQtrônica.

\section{Considerações finais}

Com base no texto pertencente ao gênero digital HQtrônica analisado, buscamos identificar as principais características do gênero e o que pode ser analisado nas capacidades de linguagem e nos estudos de multimodalidade e ressemiotização.

A partir das análises realizadas, podemos afirmar que o gênero digital HQtrônica é um importante objeto de estudo a ser utilizado pelo professor para o ensino das capacidades de linguagem do gênero, bem como da leitura em língua inglesa, além disso, o professor estará utilizando os recursos tecnológicos que estão presentes na vida dos alunos, despertando o interesse e a motivação dos mesmos pelas aulas e pela língua inglesa.

Além disso, nas análises, estão explícitos os aspectos que podem ser ensinados, os quais servirão de base para dar continuidade a uma proposta de modelização e transposição didática e elaboração de sequências didáticas, que poderão ser aplicadas na prática pedagógica.

A HQtrônica analisada proporciona aos alunos muito mais do que diversão e entretenimento, pois traz à tona temas sobre ética, justiça, levando à reflexão e à análise crítica de assuntos ligados à sociedade de um modo geral. Dessa forma, é possível utilizar o gênero em sala de aula, principalmente no ensino de línguas, visto que na BNCC (BRASIL, 2017) há 
apontamentos para o uso de gêneros digitais na sala de aula a fim de prover espaços de reflexão crítica e posicionamento ativo sobre questões éticas, políticas e culturais, entre outras.

Também é possível que o professor trabalhe em sala de aula com os diferentes recursos utilizados na HQtrônica, como, por exemplo: os balões, os tipos de discurso, o narrador, personagens e o vocabulário, explorando todos o universo lexical presente na narrativa.

E, por fim, o ensino desse gênero permite que todos os recursos semióticos sejam objetos de estudo, sendo possível fazer com que os alunos percebam e entendam a importância das animações dos personagens, dos efeitos sonoros, da diagramação dinâmica, dos cenários, entre outros. Desse modo, todos esses recursos ressemiotizados podem ser explorados pelo professor a fim de aprofundar o nível de compreensão oral e leitora dos alunos.

Enfim, esta análise traz contribuições para que o pesquisador ou professor possa elaborar um modelo didático do gênero para posterior produção de sequências didáticas, com o intuito de desenvolver nos alunos a apropriação das capacidades de linguagem, bem como o domínio do gênero. Dessa forma, o professor poderá despertar e desenvolver nos alunos o pensamento crítico, além de trabalhar com orientações sobre o uso correto das mídias digitais, as quais, além do entretenimento, permitem a aprendizagem dos mais variados assuntos.

\section{Referências}

BAKHTIN, M. Estética da criação verbal. Tradução de Maria Ermantina Galvão. G. Pereira. 2. ed. São Paulo: Martins Fontes, 1997.

BAKHTIN, M. Os gêneros do discurso. In: BAKHTIN, M. Estética da criação verbal. Trad. Paulo Bezerra. 4. ed. São Paulo: Martins Fontes, 2003.

BRASIL. Base Nacional Comum Curricular (BNCC). Brasília: MEC. 2017. Disponível em: < http://basenacionalcomum.mec.gov.br/images/BNCC_20dez_site.pdf > Acesso 20 maio 2019.

BRONCKART, J. P. Atividade de linguagem, textos e discursos. Por um interacionismo sociodiscursivo. Trad. Anna Rachel Machado, Péricles Cunha, 2. ed. São Paulo: EDUC, 2012.

COSTA, E.G. de M. Literatura e Ensino de Línguas Estrangeiras. In: GIMENEZ, K.M.P. Contribuições na área de línguas estrangeiras. Londrina: Moriá, 2005, vol. 1, p. 17-28.

CRISTOVÃO, V. L. L.; STUTZ, L. Sequências didáticas: semelhanças e especificidades no contexto 
francófono como LI e no contexto brasileiro como LE. In: SUNDY, P. T. C.; ARAÚJO, J. C.; NICOLAIDES, C. S.; SILVA, K. A. (Org). Linguística Aplicada e Sociedade: ensino e aprendizagem de línguas no contexto brasileiro, Campinas, SP. Pontes, 2011. P. 17 - 39.

DIONISIO, Ângela Paiva. Gêneros multimodais e multiletramento. In: KARWOSKI, A.M.; GAYDECZKA, B.; BRITO, K.S. (Orgs.). Gêneros textuais: reflexões e ensino. Palmas e União da Vitoria, PR: Kaygangue, 2005.

DOLZ, J.; NOVERRAZ, M.; SCHNEUWLY, B. Sequências didáticas para o oral e a escrita: apresentação de um procedimento. In: SCHNEUWLY, B.; DOLZ, J. et al. Gêneros orais e escritos na escola. Trad. e org. Roxane Rojo e Glaís Sales Cordeiro. Campinas: Mercado de Letras, 2004. p. 95-128.

FRANCO, E. S.. HQtrônicas: do suporte papel à rede Internet. 2 ed. São Paulo: Annablume \& Fapesp, 2008.

Hqtrônica: Batman - Legends Of The Dark Knight - parte 1 (Batman - O cavaleiro das Trevas. Disponível em: https://www.youtube.com/watch?v=G6KS z|9uBQ. Acesso em: 20 de setembro de 2010.

IEDEMA, R. Multimodality, resemiotization: extending the analysis of discourse as multisemiotic practice. New South Wales, Sydney, Austrália: Sage Publications, 2003.

KRESS, G.; LEEUWEN, T. V. Introdução. In: Reading images: the grammar of visual design. 2 ed. London: Routlegde, 2006.

MACHADO, A. R. . Linguagem e Educação: o trabalho do professor em uma nova perspectiva. Campinas, SP: Mercado de Letras, 2009, 174 p.

MACHADO, A. R.; CRISTOVÃO, V. L. L. A construção de modelos didáticos de gêneros: aportes e questionamentos para o ensino de gêneros. In: BONINI, A. S. FURLANETTO, M. M. (orgs) Gêneros textuais e ensino-aprendizagem. Linguagem em discurso. V. 6, no 3, set/dez, 2006.

MALLET, T. Os quadrinhos e a internet: aspectos e experiências híbridas. 2009. 230 f. Dissertação (Mestrado em Artes). Escola de Belas-Artes da Universidade Federal de Minas Gerais, Belo Horizonte, 2009.

MARCUSCHI, L. A. Gêneros textuais emergentes no contexto da tecnologia Digital. In. MARCUSCHI, L. A. \& XAVIER, A. L. (Orgs.) Hipertexto e Gêneros digitais: novas formas de construção de sentido. Rio de Janeiro: Lucerna, 2005.

McCLOUD, S. Desvendando os Quadrinhos. São Paulo: M. Books do Brasil, 2005.

MORAES, R. As histórias em quadrinhos eletrônicas em Banners publicitários na Web. 2011. 175 
f. Dissertação (Mestrado em Design). Curso de Mestrado em Design da Universidade Federal do Paraná, Curitiba, 2011.

PARANÁ, Secretaria do Estado da Educação. Diretrizes Curriculares da Educação Básica. Língua Portuguesa. Curitiba, 2006.

SARDINHA, T. F. da Rocha. O contexto da tecnologia digital e os gêneros textuais emergentes. Em: Cadernos do CNLF, Vol. XV, № 5, t. 3. Rio de Janeiro: CiFEFiL, 2011.

SCHNEUWLY, B.; DOLZ, J. . Os gêneros escolares: das práticas de linguagem aos objetos de ensino. Revista Brasileira de Educação. ANPED: Associação Nacional de Pós-Graduação e Pesquisa em Educação, n.11, p.05, Maio, Junho, Julho, Agosto. 1999.

SCHNEUWLY, B.; DOLZ, J. Gêneros orais e escritos na escola. Tradução e organização ROJO, R; CORDEIRO, G. S. Campinas, SP: Mercado de Letras, 2004.

STUTZ, L.; BIAZI, T. M. D.O Trabalho com Gêneros Textuais via Sequências Didáticas para o Estágio Supervisionado de Língua Inglesa. In: FRANCO, A. et al. (Orgs.). Simpósio de Estudos Linguísticos e Literários da UNICENTRO. UNICENTRO, Guarapuava - PR, 2007.

Recebido em outubro de 2019.

Aprovado em dezembro de 2019. 